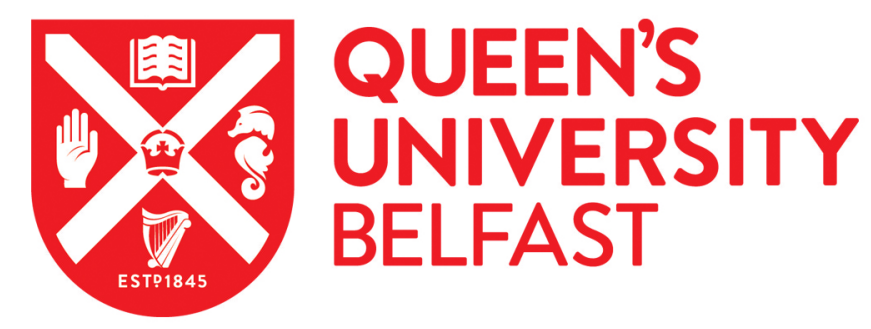

\title{
Circularly Polarized Dual Mode Wearable Implant Repeater Antenna with Enhanced Into-Body Gain
}

Conway, G., Magill, M. K., \& Scanlon, W. (2020). Circularly Polarized Dual Mode Wearable Implant Repeater Antenna with Enhanced Into-Body Gain. IEEE Transactions on Antennas and Propagation, 68(5), 3515. https://doi.org/10.1109/TAP.2020.2972335

Published in:

IEEE Transactions on Antennas and Propagation

Document Version:

Peer reviewed version

Queen's University Belfast - Research Portal:

Link to publication record in Queen's University Belfast Research Portal

Publisher rights

Copyright 2020 IEEE. This work is made available online in accordance with the publisher's policies. Please refer to any applicable terms of use of the publisher.

\section{General rights}

Copyright for the publications made accessible via the Queen's University Belfast Research Portal is retained by the author(s) and / or other copyright owners and it is a condition of accessing these publications that users recognise and abide by the legal requirements associated with these rights.

Take down policy

The Research Portal is Queen's institutional repository that provides access to Queen's research output. Every effort has been made to ensure that content in the Research Portal does not infringe any person's rights, or applicable UK laws. If you discover content in the Research Portal that you believe breaches copyright or violates any law, please contact openaccess@qub.ac.uk. 


\title{
Circularly Polarized Dual Mode Wearable Implant Repeater Antenna with Enhanced Into-Body Gain
}

\author{
Matthew K. Magill, Student Member, IEEE, Gareth A. Conway, Member, IEEE, and William G. Scanlon, Fellow, \\ IEEE
}

\begin{abstract}
A wearable stripline-fed circularly polarized dual patch antenna structure that exhibits enhanced into-body gain is presented. The antenna is designed for body-surface repeater solutions and it addresses the problem of marginal into-body deep tissue communication links, where power consumption is of the utmost importance and system link efficiency is critical. Under realistic operation conditions the antenna's circular polarization successfully mitigates implant orientation and polarization mismatch. Polarization loss for linear antennas can be up to $16 \mathrm{~dB}$ in anechoic environments and as much as $12.5 \mathrm{~dB}$ in a realistic multipath environment, as demonstrated by measured co- and cross-polar forward path gain between implanted and linearly polarized surface antennas. To overcome the body isolating effect of an antenna ground plane and to produce an effective off-body mode, a novel dual aperture stripline feed was developed which also improves the body-mounted antenna radiation efficiency. The antenna provides a $0 \mathrm{dBi}$ off-body gain whilst still maintaining excellent into-body performance. The into-body link was shown to exhibit circular polarization with a maximum isolation of only $1.5 \mathrm{~dB}$ between co- and cross-polar measurements in the 2.36-2.4 GHz band. All measurements were carried out using an accurate, next-generation layered phantom tested representative of a wide range of the population.
\end{abstract}

Index Terms-Body-centric communications, wearable, repeater, dual mode

\section{INTRODUCTION}

$\mathbf{T}$ HE adoption of wireless implantable medical devices has continued to grow in recent years, thanks to the improvements in the diagnosis and treatment of a wide range of medical conditions offered by new biotechnologies [1]. As applications continue to emerge, there is an increasing demand for implantable devices which offer new potential to solve future healthcare challenges, such as remote nerve and organ control as well as monitoring intelligent biosensors. One of the key requirements for these emerging biotechnologies is a robust, reliable and energy-efficient wireless communication link [2]. To address this challenge, on-body wearable repeater devices with adaptive antennas are an attractive solution [3][7]. These repeater antennas exhibit radiation both into and off the human body, thus enabling power efficient communication between an implanted device and an off-body external receiver at significantly increased transmission distances.

A potential issue with communication between an on-body antenna and an in-body antenna is that polarization mismatch

M. K. Magill and G. A. Conway are with the Centre for Wireless Innovation, Institute of Electronics, Communications and Information Technology, The Queen's University of Belfast, Queen's Road, Belfast, BT3 9DT, UK. Email: mmagill14; g.conway@qub.ac.uk. W. G. Scanlon is with Tyndall National Institute, Ireland. Email: w.scanlon@ieee.org. This work was supported by the Department for the Economy NI and by the UK Engineering and Physical Sciences Research Council under grant reference EP/P000983/1. may cause additional link losses which, depending on the operating scenario may cause a service outage. Furthermore, the exact orientation of an implanted device is generally not known or may change over time [8]. It would therefore be impractical to rely on the end user to align the repeater correctly. Therefore, implementing Circular Polarization (CP) in the into-body mode will increase the reliability of the intobody communication link.

Wearable design factors entail that the dual mode antenna should be in very close proximity to the human body, and for the into-body mode should effectively radiate power into the tissue. Evidently, this will produce a much lower radiation efficiency when compared with wearable antennas where the radiating element is separated from the human body by a groundplane. In [3] a dual mode antenna is presented where the off and into body modes are produced by symmetrical Koch-fractal slot antennas on both upper and lower layers, respectively, with the active mode controlled by a RadioFrequency (RF) switch. This work shows that when the bottom slot is excited, the into-body propagation is significantly improved, although the antenna to body separation of at least $40 \mathrm{~mm}$ makes this design unsuitable for close fitting wearable applications.

In another approach, radiating slots in the bottom layer of an antenna structure were used to produce radiation into the body [4], [5]. However, with a forward path gain $\left(\left|S_{21}\right|\right)$ of approximately $-26 \mathrm{~dB}$ at $5.8 \mathrm{GHz}$ with the antenna spaced $10 \mathrm{~mm}$ off the surface of the body and the in-body antenna implanted only $5 \mathrm{~mm}$ deep in $2 / 3$ muscle tissue, there is still a need for improved designs, particularly for deep tissue implant scenarios. A microstrip patch antenna can also be used to produce into-body radiation [6], [7] along with good off-body gain $(\approx 2.1 \mathrm{dBi})$. However, there remains scope to improve the effectiveness of the isolated into-body mode as a forward path gain of approximately $-50 \mathrm{~dB}$ was reported at $402 \mathrm{MHz}$ for communication distances of $25 \mathrm{~mm}$ (10 mm implant depth).

The work presented in [9] presents a multi-layer skin adhesive antenna intended as an into-to-off body repeater spaced $0 \mathrm{~mm}$ from the surface of the body. The into-body mode occurs in the $2.4 \mathrm{GHz}$ ISM band, produced by a linearly polarized curled dipole structure, with the off-body mode occurring in the 4-10.6 GHz ultra-wideband frequency band. As this antenna is spaced closely to the surface of the body, it has an adequate into-body forward path gain of approximately $-37 \mathrm{~dB}$ with an antenna implanted $30 \mathrm{~mm}$ deep in muscle tissue. However, as a consequence of this improved into body performance, it has a poor maximum off-body frequency dependant gain ranging from $-6.6 \mathrm{dBi}$ 
to $-13.5 \mathrm{dBi}$, highlighting the difficulty in optimizing both modes within the same antenna structure.

An issue with previous into-body dual mode antennas is that the main radiator into the body is blocked by the antenna's groundplane, effectively isolating it from the body, increasing its radiation efficiency [10] but consequently reducing its effectiveness as an into-body radiator. To overcome this, for the first time, a novel stripline dual aperture feeding structure exciting dual patch elements is proposed. This feeding technique allows both the top patch generating the off-body mode and the bottom patch generating the into-body mode to coexist and to be optimized independently using a single feed port in the same frequency band. To the authors' knowledge, no other dual-mode repeater antennas produce both modes in the same frequency band $(2.38 \mathrm{GHz})$ using a single feed port. The advantage of this is that it allows for much greater transceiver circuitry simplicity, as no multi-band switching or multi-port circuitry is required. This will be a requirement for future wireless implant continuous monitoring systems where a dedicated low frequency implant radio will not be needed, and a single radio interface can be used for all body-centric wireless communications. CP is implemented by exciting orthogonal modes in the bottom rectangular patch through a cross slot aperture [11], with the top patch linearly polarized.

Section II characterizes the measured maximum loss between linear on-body and in-body antennas. Section III describes the antenna solution, featuring a novel dual aperture, stripline feed structure used to excite both the into and off body modes, with a study of antenna radiation efficiency. Section IV presents the measured validation of the antenna which confirms the circular polarization and high path gain of the into-body mode while still producing $0 \mathrm{dBi}$ gain in the offbody direction. Section V briefly discusses on-body repeater system considerations before presenting the conclusions in Section VI.

\section{BACKGROUND AND CP MEASUREMENTS}

High resolution video [12], multiple-channel neural recording devices [13] and essential security and authentication overhead [14], [15] are all examples of why future advanced wireless implant monitoring and control applications will require increased data rates. However, the frequency bands currently used in wireless implant communications such as the Medical Implant Communication Service (MICS) band (402$405 \mathrm{MHz}$ ), have limited RF bandwidth to support these higher data rates. This has prompted a focus on higher frequency bands where bandwidth is more readily available, with the 2.36-2.4 GHz band specifically set aside for Medical Body Area Network (MBAN) device communications.

This move to higher frequencies presents a number of challenges particularly in terms of antenna design and propagation characteristics. The dielectric properties of human biological tissue are frequency dependent [16], with conductivity significantly increased at higher frequencies for high water content tissues such as muscle and vital organ tissues. This results in increased in-tissue path losses and reduced

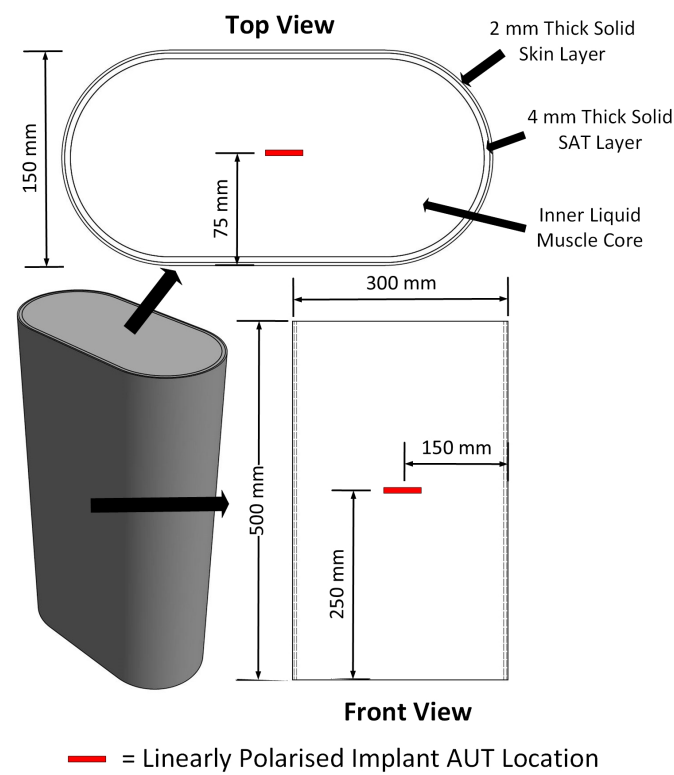

Fig. 1: Schematic of tissue phantom testbed.

implantable and wearable antenna radiation efficiencies [17], [18]. While these increased losses may be offset by the increased radiation efficiency of these normally electricallysmall antennas at higher frequencies, there is still a significant amount of propagating wave loss inherent in high frequency implantable antenna communications. This increased path loss will result in a reduction of the maximum communication distance of the implant to off-body receiver. Increasing the transmission power of the implantable transmitter would not be a viable option as this would increase the power consumption of the implanted device and also potentially introduce Specific Absorption Rate (SAR) issues. Therefore, the performance enhancement must be achieved at the surface repeater.

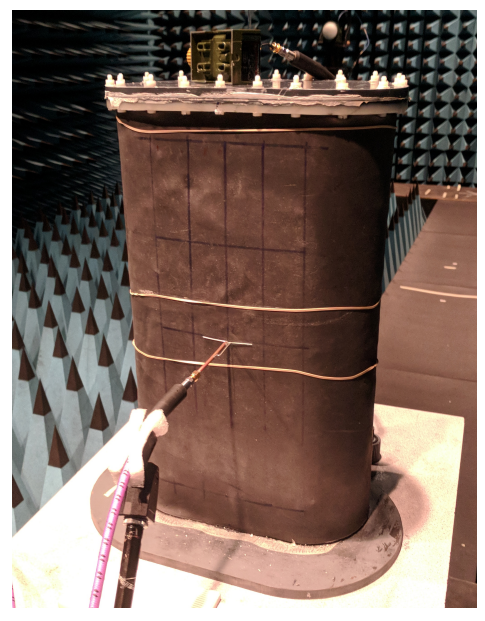

Fig. 2: Implant cross-polarization loss measurement setup in anechoic chamber. 
TABLE I: Antenna Prototype Dimensions

\begin{tabular}{|c|c|c|c|c|c|c|c|c|c|c|c|c|c|c|c|c|c|c|c|c|c|}
\hline \multirow[b]{2}{*}{ Antenna } & \multicolumn{21}{|c|}{ Dimensions (mm) } \\
\hline & $l 1$ & $l 2$ & 13 & 14 & 15 & 16 & $w 1$ & $w 2$ & $w 3$ & $w 4$ & $w 5$ & $w 6$ & $d 1$ & $d 2$ & $d 3$ & $d 4$ & $d 5$ & $d 6$ & $d 7$ & $h 1$ & $h 2$ \\
\hline DMA & 67 & 31 & 20 & 31 & 18 & 44.5 & 65 & 31 & 2 & 1.2 & 2 & 37.5 & 34 & 22.5 & 4 & 0.5 & 31.9 & 6.01 & - & 3.175 & 1.28 \\
\hline SFP & 60 & 34.5 & 20 & 43 & - & - & 50 & 34.5 & 2 & 1.3 & - & - & 17.75 & 7.75 & 34 & 15.5 & 1 & 4 & 3.85 & 3.175 & 1.28 \\
\hline MPA-F & 60 & 39 & 23 & - & - & - & 50 & 36 & 3 & - & - & - & - & - & - & - & - & - & - & 5 & - \\
\hline
\end{tabular}

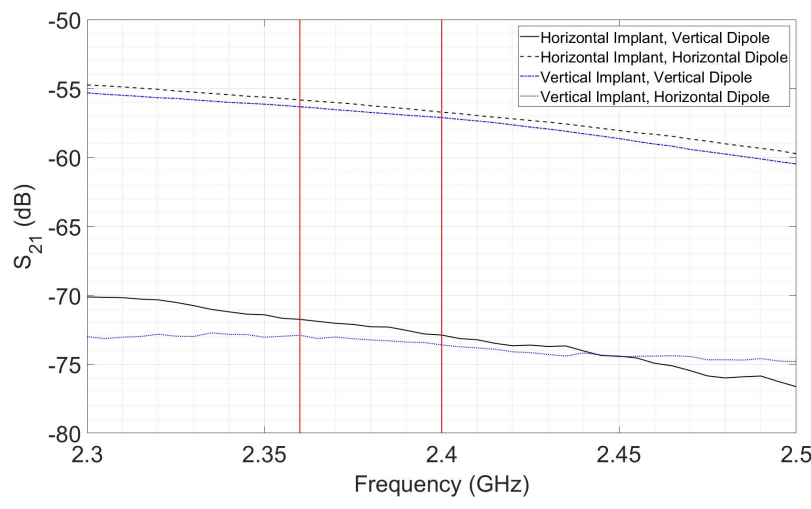

(a)

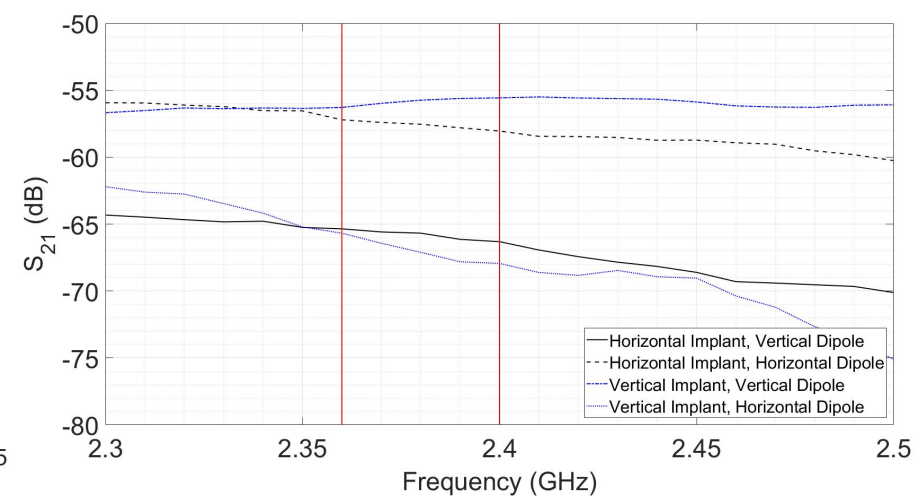

(b)

Fig. 3: Measured co- and cross-polar forward path gain $\left|S_{21}\right|$ between a horizontal and vertical in-body AUT and an on-body dipole in (a) anechoic and (b) multipath Conditions.

Many implantable antennas in literature feature CP [19][23], although the exact benefits have not been fully established. To the authors' knowledge there has been no detailed study into the potential CP losses in implanted antenna scenarios. To investigate this, CP losses between an in-body linearly polarized antenna and an external on-body linearly polarized antenna were measured. A multi-layered phantom with dimensions and shape characteristic of a human torso $300 \mathrm{~mm} \times 150 \mathrm{~mm} \times 500 \mathrm{~mm}$ was used (Fig. 1). The phantom was composed of layers with electrical properties similar to human tissue with a muscle tissue mimicking liquid core contained within a solid $4 \mathrm{~mm}$ thick Subcutaneous Adipose Tissue (SAT) mimicking tank with a $2 \mathrm{~mm}$ thick external solid skin layer. Each phantom material has the desired dielectric properties of the target tissue in the $800-2500 \mathrm{MHz}$ frequency band, with the skin layer composed of a conductive latex based on graphite powder and the SAT tank composed of a solid conductive polymer. The measured dielectric properties of all materials used in this work can be found in [24].

To measure the co-polarization losses that would be encountered by a wearable antenna in close proximity to the human body surface, a linearly polarized Printed Folded Meandered Dipole (PFMD) antenna, detailed in [24], was implanted in the muscle liquid in the geometric centre of the phantom as shown in Fig. 1. This relatively deep implantation depth of $75 \mathrm{~mm}$ in high water content tissue will provide a worst case measurement of into-body performance, ensuring successful operation in clinical applications. To reduce the effect of cable radiation [25] a small 0603 case style $2.3-2.7 \mathrm{GHz}$ chip balun was placed at the input terminals of the PFMD and the arrangement was such that there was a significant volume of muscle mimicking liquid surrounding the feed cable to dampen spurious cable radiation [26].

A half wave dipole antenna with an integrated balun, resonant in the 2.36-2.4 GHz MBAN band mounted on-body, was placed $5 \mathrm{~mm}$ from the surface of the front face of the phantom directly above the implanted Antenna Under Test (AUT). The forward path gain $\left|S_{21}\right|$ between the implanted AUT and the external dipole was then measured using an $R \& S$ ZVB-8 Vector Network Analyzer (VNA). Co-polar and crosspolar $\left|S_{21}\right|$ were measured by rotating the external dipole with the implanted PFMD fixed in the horizontal orientation shown in Fig. 1. Then the co- and cross-polar measurements were repeated with the implanted PFMD rotated $90^{\circ}$ to a vertical orientation relative to the front face of the phantom. This was repeated in both anechoic and multipath environments, with the anechoic measurement set-up shown in Fig. 2.

The results are shown in Fig. 3(a) and Fig. 3(b) for an anechoic and multipath environment, respectively. The results show a significant isolation between co- and cross-polar measurements, even in the non-anechoic conditions of a typical RF test lab where significant multipath is present. This is likely due to the high loss phantom materials already heavily attenuating the propagating waves by the time they reach the surface of the phantom, reducing the effectiveness of the multipath scattering in reinforcing the cross-polar measurement. These measurements show that there is a maximum $16.5 \mathrm{~dB}$ and $12.5 \mathrm{~dB}$ potential polarization mismatch loss in anechoic and typical multipath environments, respectively. In an implanted medical device scenario where the exact orientation can vary, such losses may not be tolerable as they are in addition to severe in-tissue path losses, meaning a CP into-body radiation solution is essential. 


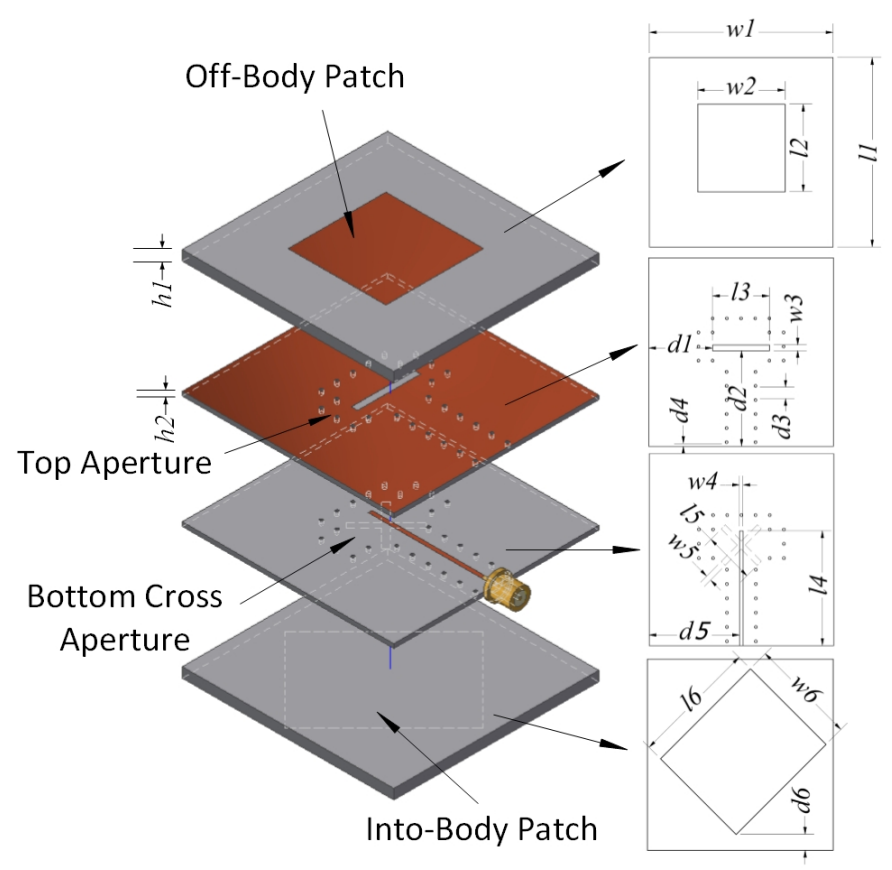

Fig. 4: DMA structure.

Indeed, CP has been implemented in previous implant antenna designs [19]-[21]. However, with the need to maintain an extremely compact antenna structure within the body, it is logical to implement the $\mathrm{CP}$ on the surface antenna where volume is not at such a premium. Nonetheless, the into-body antenna at the surface needs to be highly effective to overcome the $3 \mathrm{~dB} \mathrm{CP}$ to linear polarization mismatch loss, while still maintaining an effective off-body mode. This was the prime design aim of the antenna presented in Section III.

\section{CP Dual Mode Antenna}

A low profile, dual patch, on-body Dual Mode Antenna (DMA) with high gain CP into-body radiation is proposed. The dimensions are detailed in Table I and the structure shown in Fig. 4. The antenna is designed for use in the $2.36-2.4 \mathrm{GHz}$ MBAN band. The prototype antenna, pictured in Fig. 9, is fed via SMA connector and at $8.9 \mathrm{~mm}$ in height is suitable for wearable applications.

A major issue with previous into-body dual mode antennas is that the main radiator into the body is blocked by the antenna's groundplane, effectively isolating it from the body. An inverted patch (patch element facing the body, groundplane facing off-body) design was chosen to generate a characteristic patch-like high gain into-body mode. This raised the issue that with this type of design, the off-body mode would now be extremely degraded due to the groundplane. To overcome this, a novel stripline dual aperture feeding structure exciting dual patch elements was implemented for back to back patch elements [27], [28].

The dual aperture feeds allow both the top patch generating the off-body mode and the bottom patch generating the intobody mode to be optimized independently, using a single feed port in the same frequency band. CP is implemented

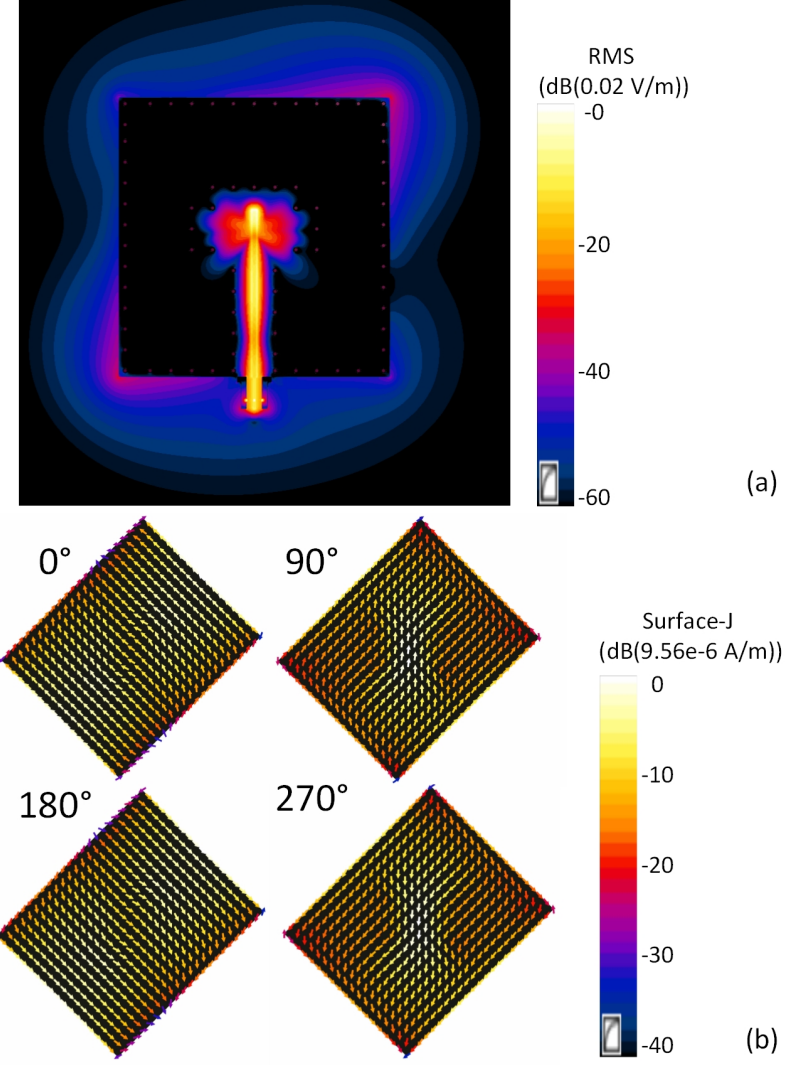

Fig. 5: (a) Simulated E-field XY slice through DMA stripline feed (top) (b) simulated surface current distribution on bottom (into-body) patch.

by feeding the bottom rectangular patch through a cross slot aperture [11], with the varying surface current vectors with phase shown in Fig. 5 (b) illustrating the CP into-body mode. The gain in either direction (off or into body) can be optimized by varying the slot aperture length feeding either patch which produces either mode, as this controls feed coupling to the specific patch element. This can be demonstrated using a free space DMA Finite Difference Time Domain (FDTD) simulation model as seen in Fig. 6.

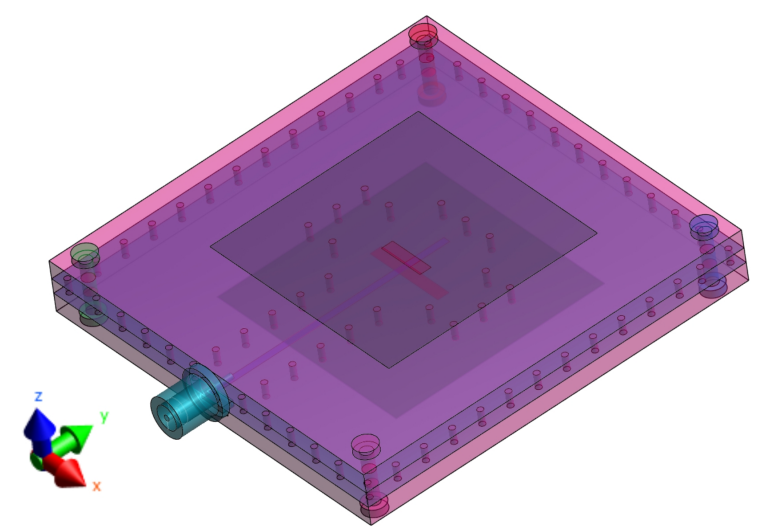

Fig. 6: DMA simulation model with top and bottom slot apertures lengths $8 \mathrm{~mm}$ and $14 \mathrm{~mm}$, respectively. 


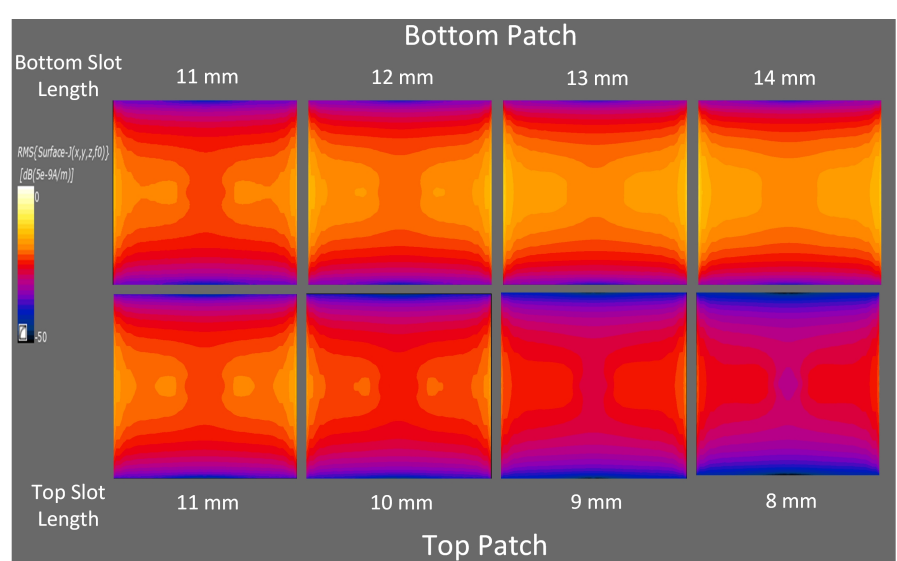

Fig. 7: DMA top and bottom patch surface current variation with aperture length variation.

The freespace DMA model has the same dimensions detailed in Table I but with identical symmetrical top $(+z$ direction) and bottom (-z direction) square patches $37 \mathrm{~mm}$ x $37 \mathrm{~mm}$ in dimension. Both patches are excited through, initially, identical and symmetrical, linear slot apertures $11 \mathrm{~mm}$ x $2 \mathrm{~mm}$ in dimension. Decreasing or increasing the slot aperture length decreases or increases the degree of coupling to each patch element, which can be seen in the varying RMS surface current distributions on both patch elements in Fig. 7. Fig. 8 shows the gains produced by both patches in the $y z$ cut shown in Fig. 6. We see from this figure that with identical slot dimensions, the gains in both directions is identical $(4 \mathrm{dBi})$ with an omnidirectional pattern in the $x z$ cut. However, by reducing the length of the top slot and increasing the length of the bottom slot, we see the gains produced by their respective patch elements reducing $\left(0^{\circ}\right)$ and increasing $\left(180^{\circ}\right)$ linearly. We can see maximum gain variation of $-0.5 \mathrm{dBi}$ versus $6 \mathrm{dBi}$ for top and bottom slot dimensions of $8 \mathrm{~mm}$ and $14 \mathrm{~mm}$ respectively, demonstrating how the gains produced by either patch element can be easily adjusted.

An antenna with high into-body gain where the radiating element is in close proximity to the body surface is going to couple heavily to the tissue and suffer from reduced radiation efficiency. To overcome this, the two patch elements were aperture fed via a common stripline feed. Stripline feeds are used due to their non-radiative and non-dispersive properties when compared with a standard microstrip line feed. This approach reduced feed dispersion and loss thereby increasing radiation efficiency of the antenna. This can be seen in Fig. 5 (a), which shows a high E-field concentration around the feed line and aperture, but minimal concentration elsewhere.

A comparative study was undertaken to further demonstrate the improved performance of the DMA antenna design. Fundamental patch antennas with identical sized groundplanes, resonant in the 2.36-2.4 GHz band, were developed; one patch stripline aperture fed and the other patch microstrip line fed. Each antenna is SMA fed and their dimensions detailed in Table I and layouts shown in Fig. 10.

Taconic TLY-3 $\left(\varepsilon_{\mathrm{r}}=2.33, \sigma=0.0026 \mathrm{~S} / \mathrm{m}\right)$ was used as the substrate for the Fundamental Microstrip Patch Antenna

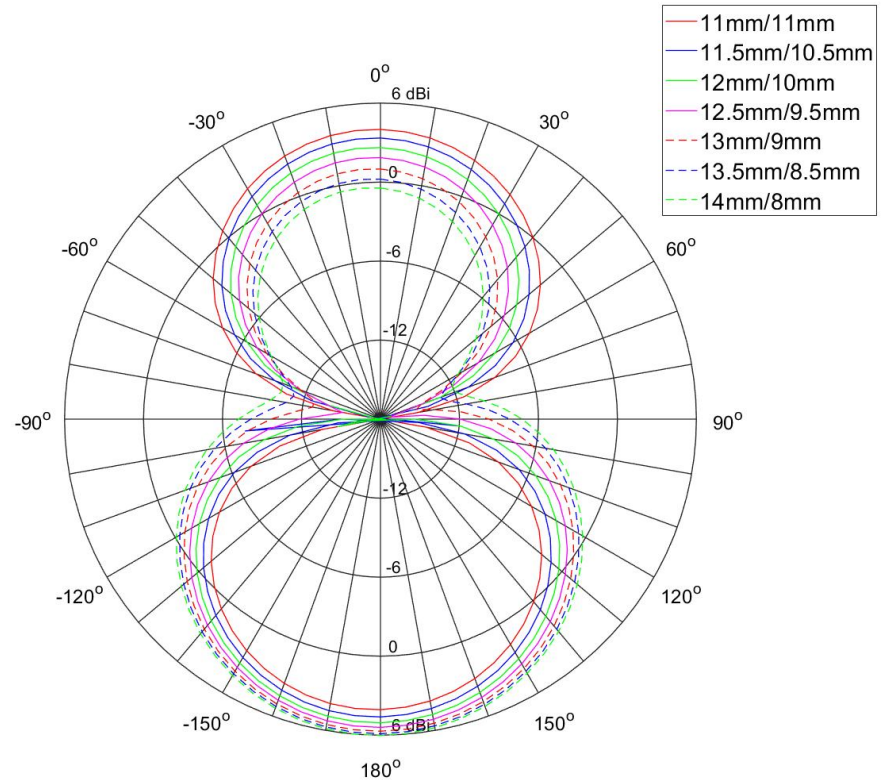

Fig. 8: XY cut far field pattern showing gain variation of both patches based on varying slot aperture lengths.

(MPA-F). Rogers RO3006 $\left(\varepsilon_{\mathrm{r}}=6.15, \sigma=0.00085 \mathrm{~S} / \mathrm{m}\right)$ was used as the substrate for the two stripline feed layers in the Stripline Fed Patch (SFP) with Rogers RT/duroid $5870\left(\varepsilon_{\mathrm{r}}=\right.$ $10.2, \sigma=0.0014 \mathrm{~S} / \mathrm{m}$ ) used as the patch substrate. Rogers RO3006 was also used as the substrate for the stripline feed layers of the DMA with Rogers RT/duroid $5880\left(\varepsilon_{\mathrm{r}}=2.2\right.$, $\sigma=0.0001 \mathrm{~S} / \mathrm{m})$. All multi-layered prototype antennas were held together using nylon M2 nuts and bolts. For the stripline fed antennas, shorting vias between the two ground planes were placed around the feed line and apertures at spacings of approximately $\lambda / 12$ for parallel-plate mode suppression [29]. All antennas were designed in simulation using the FDTD fullwave EM simulation software Sim4Life by Zurich MedTech.
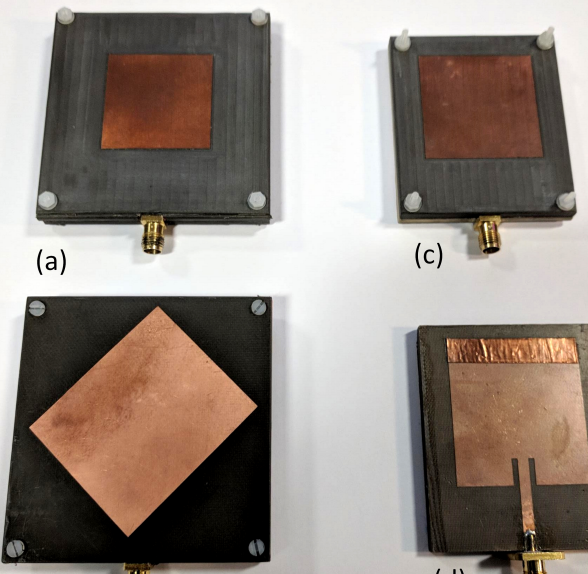

(b)

(c)

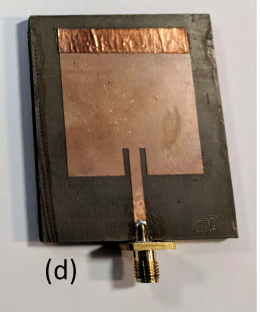

Fig. 9: Prototype antennas. (a) DMA (top). (b) DMA (bottom). (c) SFP. (d) MPA-F. 


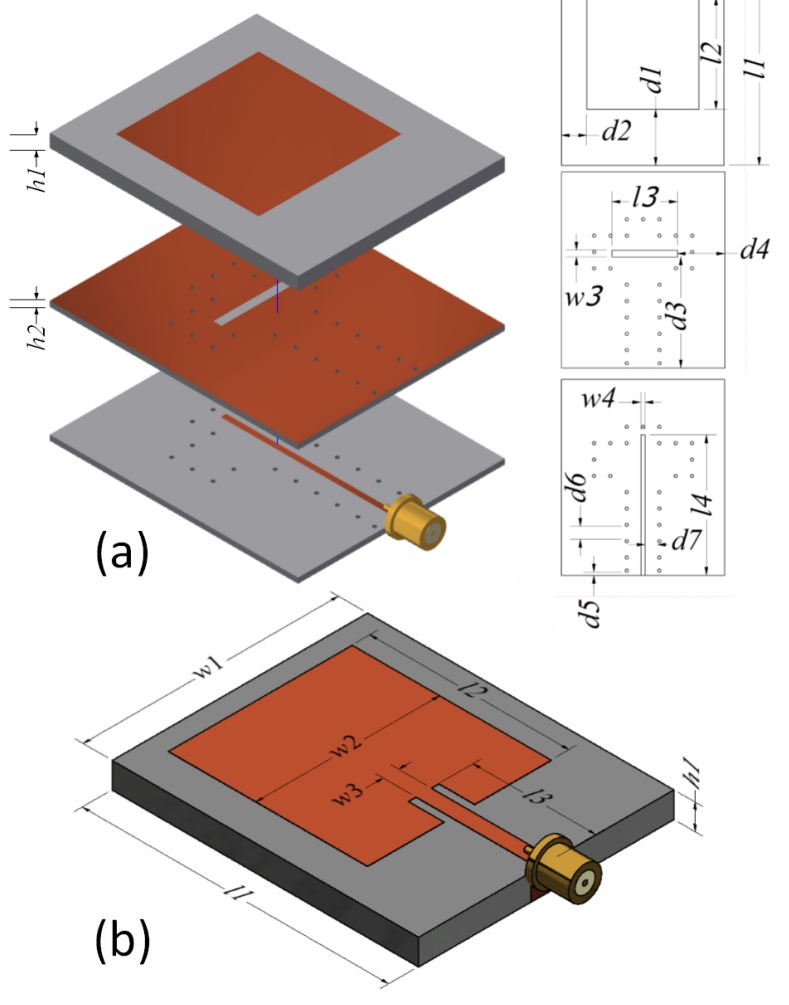

Fig. 10: (a) SFP Layout. (b) MPA-F Layout.

\section{Measurement Results}

\section{A. Return Loss}

The $\left|S_{11}\right|$ values of each antenna were measured mounted $5 \mathrm{~mm}$ from the surface of the phantom described in Section II using Rohacell HF-51 foam. The measured versus simulated results are shown in Fig. 11. As can be seen in Fig. 11(a), the DMA prototype antenna exhibits an excellent in-band return loss of less than $-10 \mathrm{~dB}$. The measured resonant frequency of the DMA prototype $(2.397 \mathrm{GHz})$ is slightly higher than the simulated resonant frequency $(2.374 \mathrm{GHz})$, due to the difficulty associated with in-house manufacturing of stripline based prototype antennas potentially introducing air gap and shorting via issues in the feed layer. The return loss performances of the SFP and MPA-F can be seen in Fig. 11(b) and Fig. 11(c), respectively. These antennas also maintain an excellent in-band return loss performance, with good agreement between measured and simulated results.

\section{B. Into-Body and CP Performance}

To measure the into-body radiation performance of the DMA, the PFMD antenna was placed in the geometric centre of the phantom, implanted in muscle liquid $75 \mathrm{~mm}$ from the phantom's surface. The DMA was then placed directly over the implanted antenna, spaced $5 \mathrm{~mm}$ from the surface of the phantom using Rohacell HF-51 foam. The $\left|S_{21}\right|$ forward path gain between the two antennas was then measured in an anechoic chamber. The implanted antenna was then rotated $90^{\circ}$ and the measurement repeated.

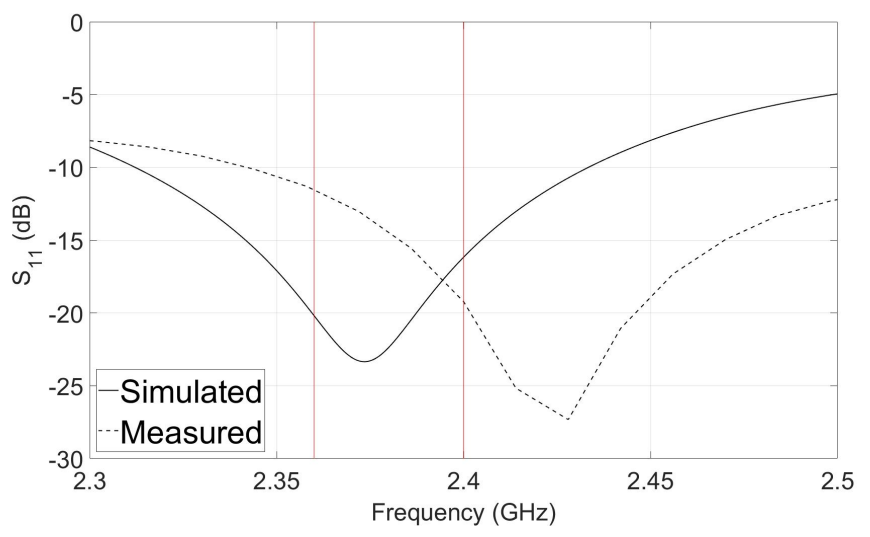

(a) DMA return loss.

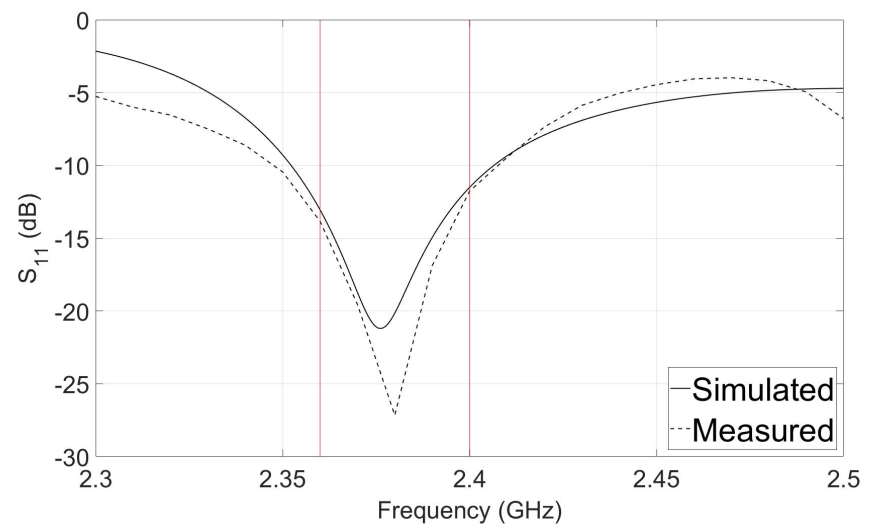

(b) SFP Return Loss

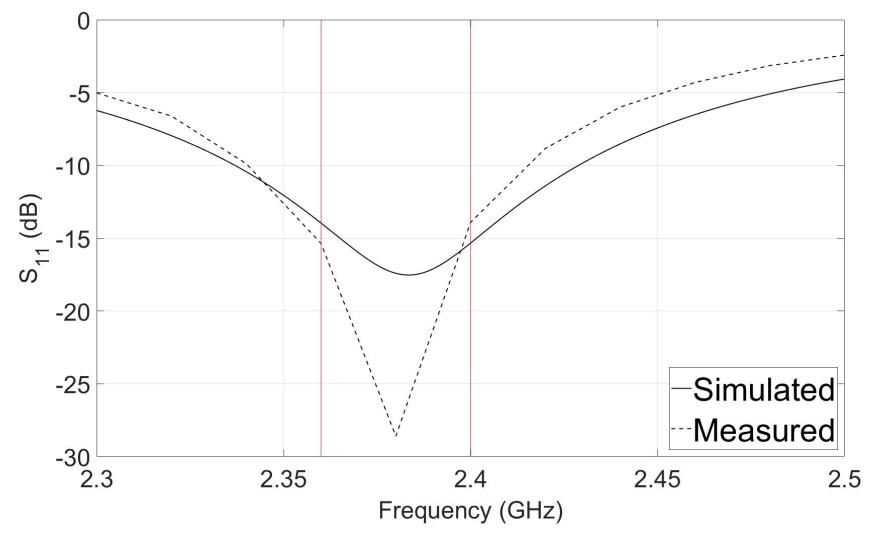

(c) MPA-F Return Loss

Fig. 11: Measured and Simulated Prototype Antenna Return Loss

The measured $\left|S_{21}\right|$ values are shown in Fig. 12(b) in the frequency range of 2.3-2.5 GHz. This shows the excellent into-body CP performance of the DMA in the band of interest, as the co- and cross-polar $\left|S_{21}\right|$ values vary no more than $1.6 \mathrm{~dB}$ in the $2.36-2.4 \mathrm{GHz}$ MBAN band. This is confirmed by Fig. 12(a), which shows the simulated versus measured Axial Ratio (AR) of the DMA. The DMA was shown to have a measured and simulated $-3 \mathrm{~dB}$ AR bandwidth of approximately $80 \mathrm{MHz}$ and $90 \mathrm{MHz}$, respectively, with good agreement between measurement and simulation. 


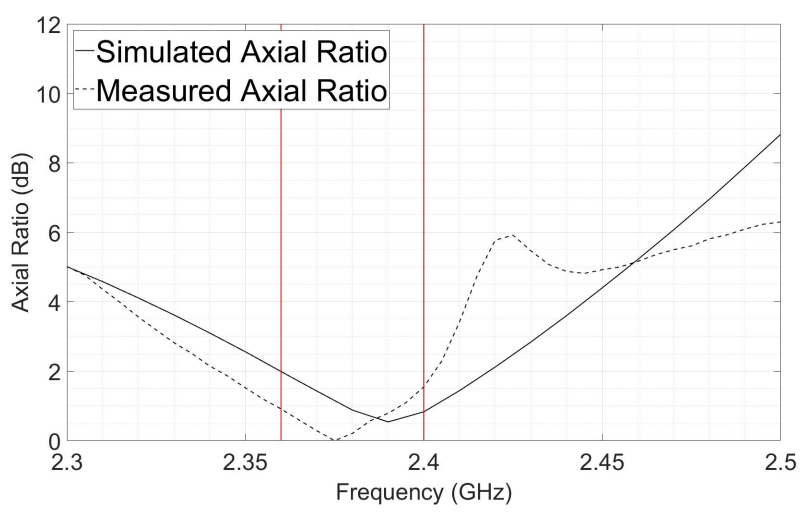

(a)

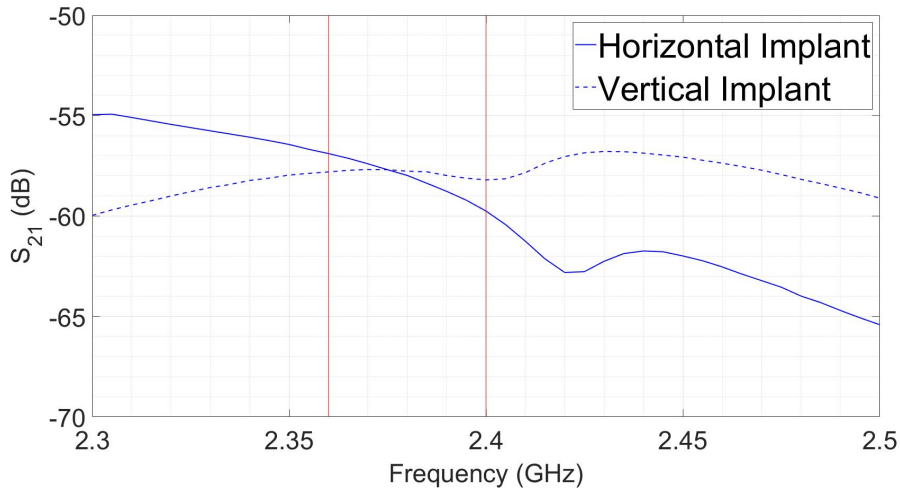

(b)

Fig. 12: (a) Simulated and measured DMA axial ratio into-body. (b) Measured forward path gain $\left|S_{21}\right|$ between the phantom mounted DMA and a horizontal and vertical implanted antenna.

TABLE II: Comparison of Into-Body Mode Performance between Antennas in Literature and Proposed Antenna

\begin{tabular}{|c|c|c|c|c|c|c|c|c|c|c|}
\hline Ref & $\begin{array}{c}\text { Dimensions } \\
(\mathbf{m m})\end{array}$ & $\begin{array}{c}\text { Depth } \\
(\mathbf{m m})\end{array}$ & Tissue & $\begin{array}{c}\text { Spacing } \\
(\mathbf{m m})\end{array}$ & $\begin{array}{c}\text { Into Freq. } \\
\text { (MHz) }\end{array}$ & $\begin{array}{c}\text { Peak }\left|S_{21}\right| \\
(\mathbf{d B})\end{array}$ & $\begin{array}{c}\text { Attenuation } \\
(\mathrm{dB} / \mathrm{cm})^{1}\end{array}$ & $\begin{array}{l}\text { Est. }\left|S_{21}\right| @ \\
75 \mathbf{~ m m}(\mathbf{d B})\end{array}$ & $\begin{array}{l}\text { Off-Body } \\
\text { Gain (dBi) }\end{array}$ & $\begin{array}{c}\text { Max. Tx } \\
\text { Pwr (mW) }\end{array}$ \\
\hline [4] & $21 \times 15.5 \times 10.5$ & 5 & Muscle & 10 & 5800 & -26 & 12.11 & $-110.8^{2}$ & 1.27 & 11 \\
\hline [7] & $60 \times 70 \times 1.6$ & 10 & Muscle & 25 & 402 & -50 & 2.93 & $-69^{2}$ & 2.1 & - \\
\hline [9] & $17.5^{2} \times \pi \times 0.76$ & 30 & Muscle & 0 & 2400 & -37 & 4.92 & $-59.1^{2}$ & -6.6 to -13.5 & 11.9 \\
\hline This work & $67 \times 31 \times 8.9$ & 75 & Muscle & 5 & 2400 & -56 & 4.92 & -56 & -0.2 & 63.2 \\
\hline
\end{tabular}

Fig. 12(b) also highlights the advantage of the added intobody gain from the inverted patch structure. The DMA has a peak $\left|S_{21}\right|$ value of $-56.9 \mathrm{~dB}$, very similar to the dipole's peak $\left|S_{21}\right|$ value of $-55.6 \mathrm{~dB}$ despite the $\mathrm{CP}$ to linear polarization losses and without the dipole's significant cross polarization losses. This has also improved $\left|S_{21}\right|$ values in comparison to other work reported in literature, shown in Table II, despite being implanted much deeper in tissue. This is also in addition to both these modes occurring in the same frequency band, but with trade-off coming from increased antenna volume.

Despite the strong into-body mode the DMA has good SAR performance, the simulated Peak Spatial Average SAR (psSAR, as recommended in IEEE/IEC62704-1 [30]) for $1 \mathrm{~mW}$ transmission power over $1 \mathrm{~g}$ of tissue is $0.025 \mathrm{~W} / \mathrm{kg}$. This gives a maximum transmission power of $63 \mathrm{~mW}$ $(18 \mathrm{dBm})$ producing $1.6 \mathrm{~W} / \mathrm{kg}$ over 1 -g of tissue compliant with the IEEE C95.1-1999 standard [31]. This performance is good compared to other published repeater antennas in Table II, although differences in tissue spacing and antenna surface area are important factors which must be considered when making direct comparisons.

To investigate the into-body performance of the DMA with position offset, the $\left|S_{21}\right|$ forward path gain between the DMA and the implant antenna was measured in a $160 \mathrm{~mm} \times 120 \mathrm{~mm}$ grid around the implant location (at $(0,0)$ in the centre of the grid). The measurement step size was $40 \mathrm{~mm}$ along the $x$ axis and $30 \mathrm{~mm}$ along the $y$ axis with the results shown in Fig. 15 as an interpolated heat map. These results show the same measured $\left|S_{21}\right|$ distribution for both polarizations of implant antenna orientations due to the $\mathrm{CP}$ into-body radiation. The positioning error is also consistent with other published work
[6], [7], [9], with approximately a $15-20 \mathrm{~dB}\left|S_{21}\right|$ decrease with $\pm 40 \mathrm{~mm}$ offset in either the $x$ or $y$ axis direction.

\section{Radiation Efficiency}

Generating a strong into-body mode is relatively simple, as in the case of the dipole, but maintaining radiation efficiency to allow an effective off-body mode in the same frequency band is challenging. The radiation efficiency improvements created by the stripline feed as opposed to a standard microstrip line feed allow this to occur. The efficiency improvements can be seen in Fig. 16. This figure shows the simulated total radiation efficiencies of the DMA, SFP and MPA-F against their measured total radiation efficiencies mounted $5 \mathrm{~mm}$ from the surface of the phantom. The total radiation efficiencies were measured using a reverberation chamber. Fig. 16 shows that the stripline feed gives an on-body efficiency improvement of approximately $10 \%$, as both the SFP and MPA-F have same sized groundplanes. By using this feed method, the total radiation efficiency of the DMA was increased to an in-band average of $25 \%$, despite its high in-body path gain.

\section{Off-Body Radiation Performance}

Each antenna prototype was then mounted on the phantom testbed on a turntable in the quiet zone of an anechoic chamber and their co-polar and cross-polar far field patterns were then measured. This setup can be seen in Fig. 17. Fig. 18 shows the measured and simulated far field patterns of each prototype antenna at $2.38 \mathrm{GHz}$ which takes into account impedance mismatch, intrinsic antenna efficiency and phantom losses.

The measured results show excellent agreement with simulated values. Fig. 18(a) shows that the DMA has a peak offbody $\left(0^{\circ}\right.$ azimuth) gain of $-0.2 \mathrm{dBi}$.

\footnotetext{
${ }^{1}$ Attenuation constant in muscle tissue at target frequency estimated using Equation (7) in [17]

${ }^{2}$ Estimated $\left|S_{21}\right|$ at $75 \mathrm{~mm}$ implantation depth calculated using attenuation coefficient
} 

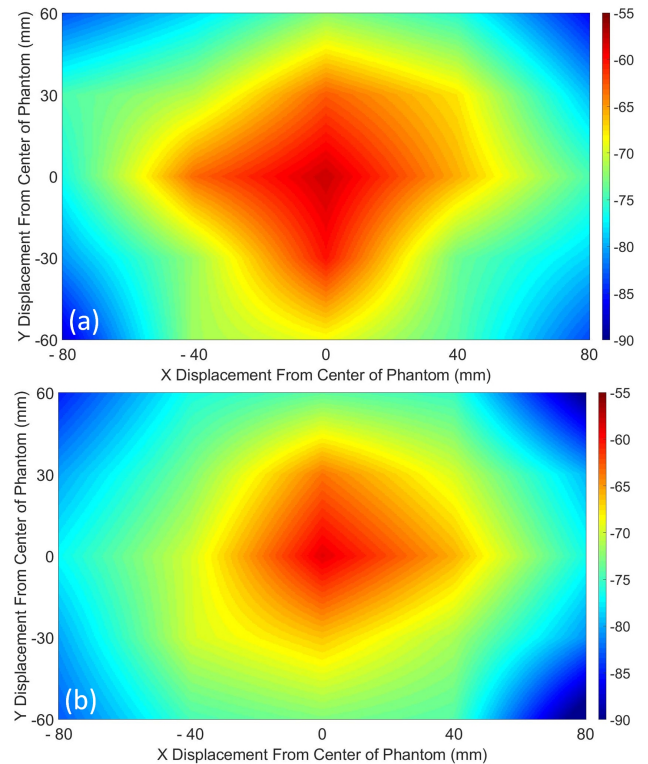

Fig. 15: Measured forward path gain $\left|S_{21}\right|$ (dB) between (a) Vertical and (b) Horizontal implanted antenna and the DMA at varying surface positions.

This is a relatively strong off-body mode considering the performance of the CP into-body mode produced by the antenna at the same frequency. As with other wearable antennas, this will be subject to body shadowing (seen in radiation pattern Fig. 18 a) and will be dependent on placement location on the surface of the body. The SFP and MPA-F were also shown to exhibit excellent off-body gain, as would be expected with a patch design. Peak off-body gains of $6.1 \mathrm{dBi}$ and $5.0 \mathrm{dBi}$ were measured for the MPA-F and SFP, respectively. The SFP had a wider measured $3 \mathrm{~dB}$ beamwidth of $96^{\circ}$ compared with the MPA-F's $85^{\circ} 3 \mathrm{~dB}$ beamwidth, explaining the slight gain reduction and making it more suitable for off-body communications, particularly in high multipath conditions.

\section{System CONSIDERATIONS}

The results presented show that, with careful design, onbody repeating antennas can provide sufficient performance to make the link between an implanted biotechnology device and wider connected health systems in the patient's local environment. In the design presented hardware complexity is also reduced as there is only one antenna feed for both the intobody and off-body modes. Nonetheless, there remain some system level considerations for a solution based on this dual mode antenna design.

Consider an MBAN implant and an MBAN off-body connection. The surface repeating system can listen for and then relay messages from the implant to the off-body receiver using either time-division duplex (TDD) or, if equipped with separate transmit and receive chains, frequency division duplex modes. If TDD is chosen then transmission latency may become an issue and there are clear implications for available throughput.

Similarly, system operation for communication from the network to the implant needs to be properly designed. An

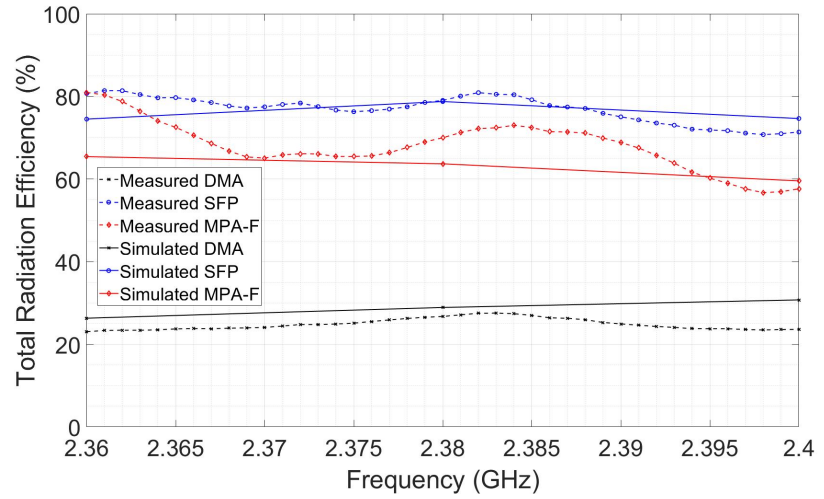

Fig. 16: AUT phantom mounted simulated and measured total radiation efficiency.

implanted device will most likely be power constrained and so the implant receiver will typically operate with a very small duty cycle. Here a surface relay can be quite advantageous as it can negotiate scheduled slots for network initiated communication and act as a local message store. Furthermore, the system designers must consider issues such as energy management for both the implant and surface nodes and in all cases it is becoming essential to consider cyber-security issues such as message authentication, privacy and encryption which becomes more complicated with a relaying system. A wearable stripline-fed DMA was presented which utilized a dual aperture fed patch to produce effective into-body and offbody modes in the same frequency range of $2.36-2.4 \mathrm{GHz}$.

\section{CONCLUSION}

In conclusion, this work has shown that cross-polarization losses are a potential major issue in implantable wireless communications. The orientation of an implant may be unknown, such as in the case of an indigestible wireless sensor, and a potential $16 \mathrm{~dB}$ of cross-polarization loss is possible which may be a major challenge in already marginal communication links.

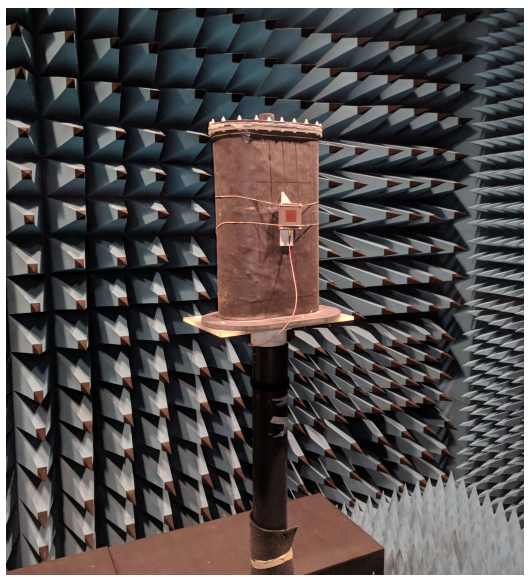

Fig. 17: Anechoic phantom mounted off-body far field pattern measurement setup. 

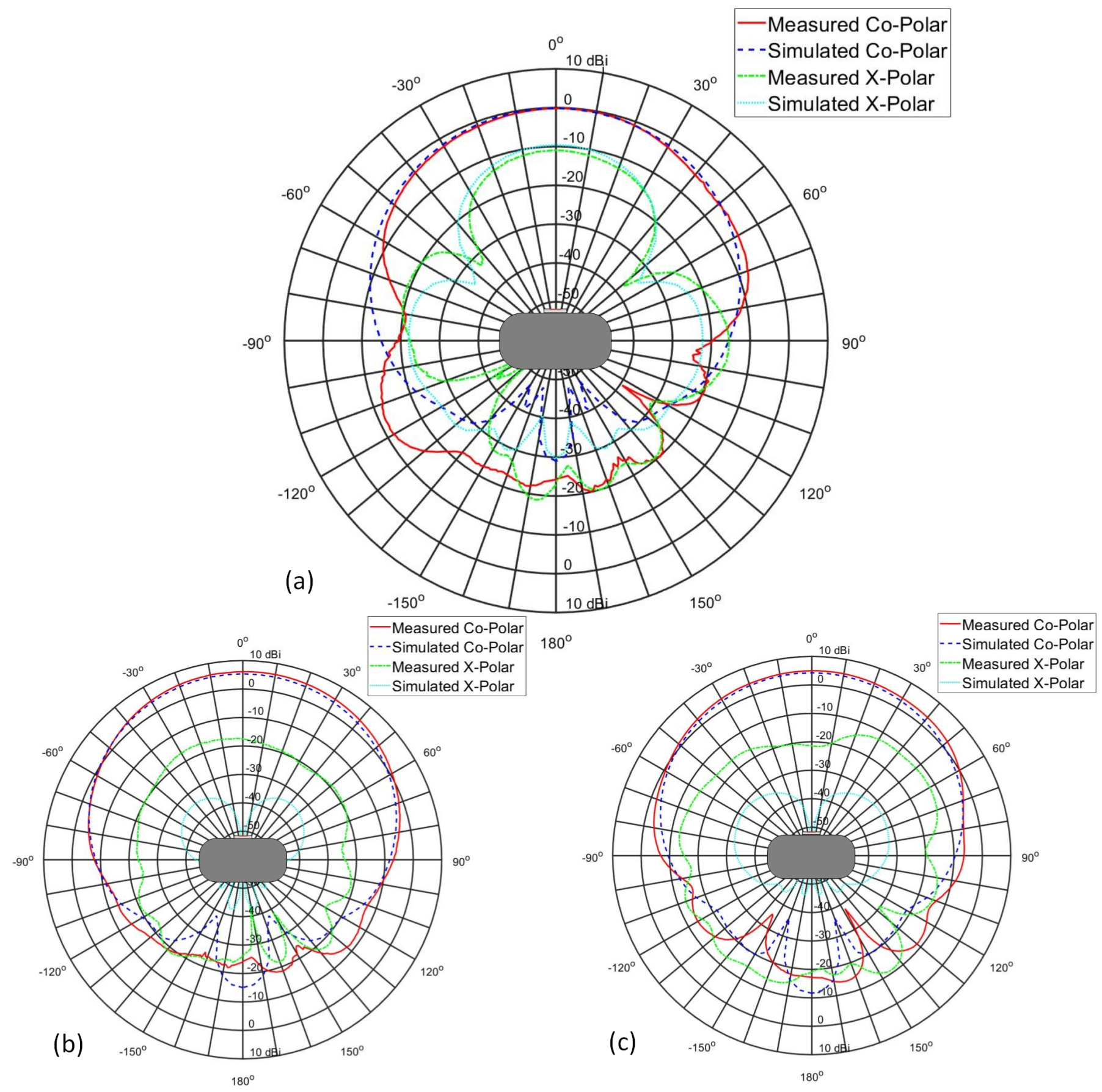

Fig. 18: Measured and simulated phantom mounted far field patterns of (a) DMA (b) MPA-F (c) SFP. 
The stripline feed was used to increase the radiation efficiency of the DMA which would suffer from efficiency losses due to tissue coupling caused by the into-body mode. The stripline feed was shown to increase wearable radiation efficiency by approximately $10 \%$ by comparing the efficiency performance of a stripline fed and microstrip line fed patch antenna with same sized ground planes. The into-body performance was shown to be excellent, thanks to the high intobody gain inverted patch structure, with $\left|S_{21}\right|$ values similar to previous work despite having a deeper implant antenna and a $5 \mathrm{~mm}$ body-surface spacing. The in-body mode was also shown to exhibit excellent CP properties in the band of interest, with only a maximum deviation between co- and cross-polar measurements of only $1.5 \mathrm{~dB}$. The DMA, despite having such an effective into-body mode, was shown to have a strong off-body mode, with a peak gain of $0 \mathrm{dBi}$.

\section{ACKNOWLEDGMENT}

We would like to thank Rogers Corp. for substrate samples used in the prototype antenna manufacture.

\section{REFERENCES}

[1] A. Kiourti and K. S. Nikita, "A review of in-body biotelemetry devices: Implantables, ingestibles, and injectables," IEEE Transactions on Biomedical Engineering, vol. 64, no. 7, pp. 1422 - 1430, Jul. 2017.

[2] G. D. Ntouni, A. S. Lioumpas, and K. S. Nikita, "Reliable and energyefficient communications for wireless biomedical implant systems," IEEE Journal of Biomedical and Health Informatics, vol. 18, no. 6, pp. $1848-1856$, Nov. 2014.

[3] S. Dumanli, "A digitally assisted repeater antenna for implant communications," in 11th European Conference on Antenna Propagation (EUCAP) 2017, Mar. 2017.

[4] J. Tak, K. Kwon, S. Kim, and J. Choi, "Dual-band on-body repeater antenna for in-on-on wban applications," International Journal of Antennas and Propagation, vol. 2013, pp. 1 - 12, Oct. 2013.

[5] K. Kwon, J. Tak, and J. Choi, "Design of a dual-band antenna for wearable wireless body area network repeater systems," in 7th European Conference on Antennas and Propagation (EuCAP) 2013, 2013.

[6] S. Agneessens, P. V. Torre, E. Tanghe, G. Vermeeren, W. Joseph, and H. Rogier, "On-body wearable repeater as a data link relay for in-body wireless implants," IEEE Antennas and Wireless Propagation Letters, vol. 11, pp. 1714 - 1717, Jan. 2013.

[7] A. Kiourti, J. R. Costa, C. A. Fernandes, and K. S. Nikita, "A broadband implantable and a dual-band on-body repeater antenna: Design and transmission performance," IEEE Transactions on Antennas and Propagation, vol. 62, no. 6, pp. 2899-2908, Jun. 2014.

[8] A.-F. B. E. Quast, F. V. Y. Tjong, B. E. Koop, A. A. M. Wilde, R. E. Knops, and M. C. Burke, "Device orientation of a leadless pacemaker and subcutaneous implantable cardioverter-defibrillator in canine and human subjects and the effect on intrabody communication," Europace, Feb. 2018

[9] J. M. Felicio, J. R. Costa, and C. A. Fernandes, "Dual-band skinadhesive repeater antenna for continuous body signals monitoring," IEEE Journal of Electromagnetics, $R F$ and Microwaves in Medicine and Biology, vol. 2, no. 1, pp. 25 - 32, Mar. 2018.

[10] G. Conway, S. Cotton, and W. Scanlon, "An antennas and propagation approach to improving physical layer performance in wireless body area networks," IEEE Journal on Selected Communications, vol. 27, no. 1, pp. 27-36, Jan. 2009.

[11] B. Al-Jibouri, H. Evans, E. Korolkiewicz, E. Lim, A. Sambell, and T. Viasits, "Cavity model of circularly polarised cross-aperture-coupled microstrip antenna," IEE Proceedings - Microwaves, Antennas and Propagation, vol. 148, no. 3, pp. 147 - 152, Jun. 2001.

[12] R. Chavez-Santiago, I. Balasingham, J. Bergsland, W. Zahid, K. Takizawa, R. Miura, and H.-B. Li, "Experimental implant communication of high data rate video using an ultra wideband radio link," in 2013 35th Annual International Conference of the IEEE Engineering in Medicine and Biology Society (EMBC), 2013.
[13] A.R.Kahn, E.Y.Chow, O.Abdel-Latief, and P.P.Irazoqu, "Low-power, high data rate transceiver system for implantable prostheses," International Journal of Telemedicine and Applications, vol. 2010, Nov. 2010.

[14] S. Challa, M. Wazid, A. K. Das, and M. K. Khan, "Authentication protocols for implantable medical devices: Taxonomy, analysis and future directions," IEEE Consumer Electronics Magazine, vol. 7, no. 1, pp. 57-65, Jan. 2018.

[15] Z. E. Ankarali, Q. H. Abbasi, A. Demir, E. Serpedin, K. Qaraqe, and H. Arslan, "A comparative review on the wireless implantable medical devices privacy and security," in 2014 EAI 4th International Conference on Wireless Mobile Communication and Healthcare (Mobihealth),, 2014.

[16] P. Hasgall, F. D. Gennaro, C. Baumgartnertner, E. Neufeld, M. Gosselin, D. P. A. Klingenbock, and N. Kuster. (2015, Sept.) Itis database for thermal and electromagnetic parameters of biological tissues. Version 3.0. [Online]. Available: www.itis.ethz.ch/database

[17] D. Kurup, W. Joseph, G. Vermeeren, and L. Martens, "In-body path loss model for homogeneous human tissues," IEEE transactions on Electromagnetic Compatibility, vol. 54, no. 3, pp. 556-564, Jun. 2012.

[18] R. Chavez-Santiago, C. Garcia-Pardo, A. Fornes-Leal, A. Valles-Lluch, G. Vermeeren, W. Joseph, I. Balasingham, and N. Cardona, "Experimental path loss models for in-body communications within $2.36-2.5 \mathrm{GHz}$," IEEE Journal of Biomedical and Health Informatics, vol. 19, no. 3, pp. 930-937, May 2015.

[19] C. Liu, Y.-X. Guo, and S. Xiao, "Capacitively loaded circularly polarized implantable patch antenna for ism band biomedical applications," IEEE Transactions on Antennas and Propagation, vol. 62, no. 5, pp. 24072417, Feb. 2014.

[20] W. Lei, H. Chu, and Y.-X. Guo, "Design of a circularly polarized ground radiation antenna for biomedical applications," IEEE Transactions on Antennas and Propagation, vol. 64, no. 6, pp. 2535 - 2540, Jun. 2016.

[21] R. Das and H. Yoo, "A wideband circularly polarized conformal endoscopic antenna system for high-speed data transfer," IEEE Transactions on Antennas and Propagation, vol. 65, no. 6, pp. 2816 - 2826, Jun. 2017.

[22] H. Bahrami, S. A. Mirbozorgi, R. Ameli, L. A. Rusch, and B. Gosselin, "Flexible, polarization-diverse uwb antennas for implantable neural recording systems," IEEE Transactions on Biomedical Circuits and Systems, vol. 10, no. 1, pp. 38 - 48, Feb. 2016.

[23] Z. Duan and L. jie Xu, "Dual-band implantable antenna with circular polarisation property for ingestible capsule application," Electronic Letters, vol. 53, no. 16, pp. 1090 - 1092, Aug. 2017.

[24] M. K. Magill, G. A. Conway, and W. G. Scanlon, "Tissue-independent implantable antenna for in-body communications at 2.36-2.5 ghz," IEEE Transactions on Antennas and Propagation, vol. 65, no. 9, pp. $4406-$ 4417, Sept. 2017.

[25] S. Saario, D. V. Thiel, J. W. Lu, and S. G. O'Keefe, "An assessment of cable radiation effects on mobile communications antenna measurements," in Proceedings of Antennas and Propagation Society International Symposium, 1997.

[26] Y. El-Saboni, M. K. Magill, G. A. Conway, S. L. Cotton, and W. G. Scanlon, "Measurement of deep tissue implanted antenna efficiency using a reverberation chamber," IEEE Journal of Electromagnetics, RF and Microwaves in Medicine and Biology, vol. 1, no. 2, pp. 90 - 97, Dec. 2017.

[27] H. Iwasaki, "A back-to-back rectangular-patch antenna fed by a cpw," IEEE Transaction on Antennas and Propagation, vol. 46, no. 10, pp. 1527 - 1530, Oct. 1998.

[28] K. Yang, X. Bao, P. McEvoy, and M. J. Ammann, "Pattern reconfigurable back-to-back microstrip patch antenna," IET Microwaves, Antennas \& Propagation, vol. 10, no. 13, pp. 1390 - 1394, Oct. 2016.

[29] A. Bhattacharyya, O. Fordham, and Y. Liu, "Analysis of stripline-fed slot-coupled patch antennas with vias for parallel-plate mode suppression," IEEE Transaction on Antennas and Propagation, vol. 46, no. 4, pp. 538 -545, Apr. 1998.

[30] Determining the peak spatial-average specific absorption rate $(S A R)$ in the human body from wireless communications devices, $30 \mathrm{MHz}$ to 6 $\mathrm{GHz}$ - Part 1: General requirements for using the finite-difference timedomain (FDTD) method for SAR calculations, IEC/IEEE 62704-1 Std.

[31] IEEE Standard for Safety Levels with Respect to Human Exposure to Radio Frequency Electromagnetic Fields, $3 \mathrm{kHz}$ to $300 \mathrm{GHz}$, IEEE Standard C95.1-1999 Std., 1999. 


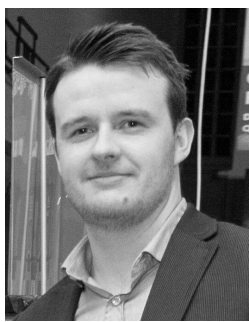

Matthew K. Magill received a Masters of Engineering degree in Electrical and Electronic Engineering (with first class honors) from the Queen's University of Belfast in 2014. In 2018, he received a $\mathrm{PhD}$ degree in Electronic Engineering entitled "Antennas and Propagation for Robust Wireless Implantable Communications", also from QUB. His research interests include implantable and wearable antenna design, computational electromagnetism, human tissue equivalent materials, implantable and wearable system test-beds and experimental test methodologies for body-centric communications.

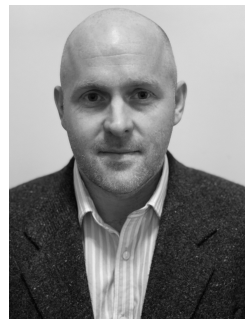

Gareth A. Conway (S'07-M'15-SM'19) received the BEng (Hons) degree in electronic systems from the University of Ulster, UK, in 2004, and the $\mathrm{PhD}$ degree in electronic engineering, entitled "Wearable Antennas for On-Body Wireless Communications" from the Queen's University of Belfast (QUB), Belfast, UK, in 2008. On completion of his doctorate, he spent three years as a Commercial Research Engineer, specializing in antennas and propagation for mobile communication. In 2011, he re-joined QUB to complete an EPSRC Knowledge Transfer Secondment with Toumaz Healthcare Ltd., Oxford, UK, undertaking research and development in 'Innovative body- worn antennas for medical devices.' In 2013, he became a Lecturer in Communications Engineering at ECIT, Queens University of Belfast. He has authored or co-authored over 40 international conference and journal papers. His current research interests include antennas, human tissue equivalent materials, wave propagation and electromagnetism for wearable and implantable communications.

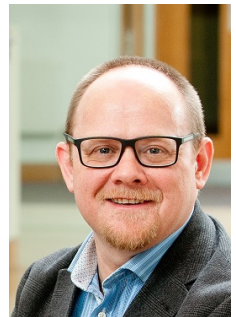

William G. Scanlon (M'98-SM'13-F'20) is Chief Executive Officer of Tyndall National Institute, Ireland. He was Senior Lecturer and Chair/Full Professor at Queens University of Belfast (UK, 20022018) and held various leadership positions such as Director of the Centre for Wireless Innovation and Head of School of Electronics, Electrical Engineering and Computer Science. He held a parttime Chair in Short Range Radio at the University of Twente, The Netherlands (2009-2014). Scanlon is a pioneer in wearable and implantable medical device communications. He has served as keynote speaker for the International Symposium on Antennas and Propagation (2018), the IEEE Intl. Microwave Workshop Series on RF and Wireless Technologies for Biomedical and Healthcare Applications (2014), the NATO Military Communications and Information Systems Conf. (2010), the Intl. Conf. on Bodynets (2010 and 2018) and the European Workshop on Conformal Antennas (2007). He was a Series Editor of the IET Book Series on Telecommunications and Networking, an inaugural Associate Editor of IEEE Journal of Translational Engineering in Health and Medicine and an Associate Editor for IEEE Antennas and Wireless Propagation Letters and is currently an Associate Editor for IEEE Open Journal in Antennas and Propagation. He holds an URSI Young Scientist award (1999), the 2010 IEEE H. A. Wheeler Prize Paper Award for IEEE Trans. Antennas and Propagation and he delivered the 2012 NATO Intl. Lecture Series on Next Generation Communications. 